\section{Check for updates}

Cite this: RSC Adv., 2020, 10, 43011

\title{
Retraction: Investigation of yellow horn (Xanthoceras sorbifolia Bunge) transcriptome in response to different abiotic stresses: a comparative RNA-Seq study
}

\author{
Yanhe Lang, ${ }^{*}$ Zhi Liu and Zhimin Zheng \\ Retraction of 'Investigation of yellow horn (Xanthoceras sorbifolia Bunge) transcriptome in response to \\ different abiotic stresses: a comparative RNA-Seq study' by Yanhe Lang et al., RSC Adv., 2020, 10, 6512- \\ 6519, DOI: 10.1039/C9RA09535G.
}

DOI: 10.1039/d0ra90119a

rsc.li/rsc-advances

We, the named authors, hereby wholly retract this RSC Advances article due to issues with the experimental design and data analysis, which were discovered after carrying out the follow-up experiments.

(1) In this study, only one control group was set in accordance to both $24 \mathrm{~h}$ and $48 \mathrm{~h}$ stress treatment. However, as a matter of fact, two control groups should have been set in the context of the two treatment times ( $24 \mathrm{~h}$ and $48 \mathrm{~h}$ ), respectively. It is assumed that the differentially expressed genes (DEGs) of yellow horn seedings should be identical without stress treatment at both $24 \mathrm{~h}$ and $48 \mathrm{~h}$, but in fact there existed some differences. And this led to the incorrect MDS analysis.

(2) Selection of treatment time ( $24 \mathrm{~h}$ and $48 \mathrm{~h}$ ) was inappropriate. In the follow-up experiments, other treatment times (i.e. $0 \mathrm{~h}$, $3 \mathrm{~h}, 6 \mathrm{~h}, 9 \mathrm{~h}$ and $12 \mathrm{~h}$ ) were tried, and it was found that after stress treatment for $6 \mathrm{~h}$ or $9 \mathrm{~h}$, almost all stress-responsive genes were up-regulated; while after treatment for $24 \mathrm{~h}$ and $48 \mathrm{~h}$, most stress-responsive genes were found to be generally down-regulated. So treatment for $6 \mathrm{~h}$ and $9 \mathrm{~h}$ may be the better choice.

(3) Salt concentration was not appropriate; $200 \mathrm{mM}$ or higher salt concentration would be better, as evidenced by transcriptomic analysis, although this still needs further evaluation via large-scale transcriptomic sequencing.

(4) The transcriptomic data was not properly administered, arranged and named in time, due to restrictions due to Covid-19. This led to errors in the subsequent bioinformatics analysis and therefore the conclusions of this paper are not supported. We therefore regretfully wish to retract the results presented in this paper and further improve the experiment. Further detailed studies using the improved methods are forthcoming.

Signed: Yanhe Lang, Zhi Liu and Zhimin Zheng

Date: $16^{\text {th }}$, October, 2020

Retraction endorsed by Laura Fisher, Executive Editor, RSC Advances 